\title{
EFFECTIVENESS OF EARTHQUAKE SELECTION AND SCALING METHOD IN NEW ZEALAND
}

\author{
Rajesh P. Dhakal ${ }^{1, *}$, Sandip Singh ${ }^{2}$ and John B. Mander ${ }^{3}$
}

\begin{abstract}
SUMMARY
In New Zealand, time history analysis is either the required or preferred method of assessing seismic demands for torsionally sensitive and other important structures, but the criteria adopted for the selection of ground motion records and their scaling to generate the seismic demand remains a contentious and debatable issue. In this paper, the scaling method based on the least squares fit of response spectra between 0.4-1.3 times the structure's first mode period as stipulated in the New Zealand Standard for Structural Design Actions: Earthquake Actions (NZS1170.5) [1] is compared with the scaling methods in which ground motion records are scaled to match the peak ground acceleration (PGA) and spectral acceleration response at the natural period of the structure corresponding to the first mode with $5 \%$ of critical damping; i.e. $\mathrm{S}_{\mathrm{a}}\left(\mathrm{T}_{1}, 5 \%\right)$. Incremental dynamic analysis (IDA) is used to measure the record-torecord randomness of structural response, which is also a measure of the efficiency of the intensity measure (IM) used. Comparison of the dispersions of IDA curves with the three different IMs; namely PGA, $\mathrm{S}_{\mathrm{a}}\left(\mathrm{T}_{1}, 5 \%\right)$ and NZS1170.5 based IM, shows that the NZS1170.5 scaling method is the most effective for a large suite of ground motions. Nevertheless, the use of only three randomly chosen ground motions as presently permitted by NZS1170.5 is found to give significantly low confidence in the predicted seismic demand. It is thus demonstrated that more records should be used to provide a robust estimate of likely seismic demands.
\end{abstract}

\section{INTRODUCTION}

Performance based earthquake engineering (PBEE) relies on structural performance being predicted with a known and acceptable level of confidence. Steps such as hazard analysis, demand prediction, damage modelling and loss estimation affect the prediction of ultimate performance [2-3]. This paper deals with the demand prediction aspect, focusing on the variation in structural response for a given suite of ground motion records. In PBEE, structural response is presented probabilistically in an intensity measure (IM) vs engineering demand parameter (EDP) domain. Significant variation in structural responses obtained through time history analyses using different ground motion records is evident even though these records may have been subjected to a rigorous selection procedure and scaled to the same intensity level. However, the extent of this record-to-record variation in IM-EDP relationship depends very much on the selection of parameters to be used as IM and EDP. The variation of structural response for a given seismic hazard level has been shown to match reasonably with a lognormal distribution [45]. Therefore, if the IM is chosen to significantly reduce the lognormal standard deviation (dispersion) of the responses, fewer records and hence fewer analyses can yield the same level of confidence in the predicted seismic demand.

Peak ground acceleration (PGA) and spectral acceleration at the natural period of structure; i.e. $\mathrm{S}_{\mathrm{a}}\left(\mathrm{T}_{1}\right)$, are commonly used as IM because they are either readily available or easily computable. The effectiveness of an IM is discussed in terms of its 'sufficiency' and 'efficiency'. An IM must be 'sufficient'; i.e. the structural response at a constant value of the selected IM must be independent of seismological parameters, such as earthquake magnitude and source-to-site distance. An efficient IM will reduce the variability of structural response. For most cases, $\mathrm{S}_{\mathrm{a}}\left(\mathrm{T}_{1}\right)$ has been identified to be more efficient than PGA [4]. However, even $S_{a}\left(T_{1}\right)$ has been found short in 'sufficiency' and 'efficiency' in some special cases such as tall buildings where higher order modes may play a significant role in the overall response [6-8]. A similar situation arises in the case of soft-soil or near-source ground motion when the dominant frequency of the ground motion is likely to be significantly higher than the first mode frequency of a structure. The quest to overcome these shortcomings has led to investigations of other forms of scalar IMs [9-10] and vector IMs [7,11].

In contrast, the search of a more efficient EDP which correlates better with damage, although acknowledged to be equally important, has found significantly less attention from researchers. The most common EDP used by researchers to deal with structural damage is the absolute maximum interstory drift and the peak floor acceleration has been unanimously accepted as the EDP to correlate better with non-structural content damage. Apart from these, only the maximum value of the average drift of a building [12] and the average of the positive and negative interstory drift peaks [13] have been investigated as EDPs (for structural damage purpose) in the authors' knowledge.

\footnotetext{
${ }^{1}$ Senior Lecturer, Department of Civil Engineering, University of Canterbury

2 Graduate Student (Formerly), Department of Civil Engineering, University of Canterbury

${ }^{3}$ Professor, Department of Civil Engineering, Texas A\&M University

*Corresponding Author:Ph:03-3642987x7673, Fax:03-3642758,Email: rajesh.dhakal@canterbury.ac.nz
} 
In this paper, using the absolute maximum interstory drift as EDP, the efficiency of three different IMs including the one recommended in the New Zealand Standard for Structural design actions: Part 5: Earthquake actions (NZS1170.5:2004) [1] is scrutinised. In New Zealand, time history analysis can be used for seismic design of all structures and is compulsory for designing torsionally sensitive structures. NZS1170.5 [1] prescribes that time history analysis shall be conducted with at least three ground motion records and the most severe demand be used in design. Each of these three ground motion records are scaled to match the design response spectrum for the target limit state and the location of the structure to be designed. The ground motions are to be selected from actual records (wherever possible) that have seismological features similar to the target design spectrum of the site. The selected records are scaled using two factors; a record scale factor $\mathrm{k}_{1}$ and a family scale factor $k_{2}$. The record scale factor $k_{1}$ is chosen to minimise in a least squares sense the logarithm of the ratio of spectral accelerations of the scaled record spectrum to the target design spectrum over a range of period between 0.4-1.3 times the structure's first mode period $T_{1}$. The family factor $k_{2}$ is decided such that the energy content of at least one record in the family exceeds that of the design spectrum over the target period range. No ground motion records with $\mathrm{k}_{1}$ factor outside the allowable range of 0.33-3 are permitted. Moreover, if the structure is within $20 \mathrm{~km}$ of a fault, then one of the three records needs to exhibit a forward directivity (velocity pulse) component. The effectiveness of the NZS1170.5 method of selection and scaling of ground motion records has not yet been investigated, and hence it is very timely that a study aiming to investigate the effectiveness of this approach be conducted and reported, at least in New Zealand, to ensure confidence of New Zealand designers in their design practice.

Hence, this paper compares the efficiency of three IMs namely; PGA, $\mathrm{S}_{\mathrm{a}}\left(\mathrm{T}_{1}\right)$ with $5 \%$ of critical damping; i.e. $\mathrm{S}_{\mathrm{a}}\left(\mathrm{T}_{1}\right.$, $5 \%$ ), and the least squares fit in the period range of $0.4 \mathrm{~T}_{1^{-}}$ $1.3 \mathrm{~T}_{1}$ as recommended by NZS1170.5 [1] (referred to as NZS1170.5 IM hereafter). PGA based scaling is the simplest form of scaling ground motion records. Studies have shown that it produces relatively large dispersion of responses except for structures with small natural periods [14]. On the other hand, $\mathrm{S}_{\mathrm{a}}\left(\mathrm{T}_{1}, 5 \%\right)$ produces lower dispersion of responses but it requires more effort as response spectra need to be generated prior to scaling the spectral acceleration $\left(S_{a}\right)$ ordinate at the fundamental period. Least squares fit of $\mathrm{S}_{\mathrm{a}}$ over a range of period as required by NZS1170.5 IM, which is expected to result in further lower levels of dispersion, is apparently the most cumbersome form of scaling records. The best choice of IM is disputable as a balance needs to be struck between simplicity and effectiveness in reducing record-to-record variation [2]. However, slightly increased difficulty in determining the scaling factor (which could be automated in a spreadsheet) is a far more appealing proposition than performing a significantly larger number of time history analyses with easy-to-scale but less efficient IMs.

\section{GENERAL METHODOLOGY}

The overall process of investigating the effect of various IMs on the uncertainty in structural response has been divided into the following two steps for convenience:

\section{Step 1: Conduct Incremental Dynamic Analysis (IDA)}

This involves subjecting a structural model to a suite of ground motion records scaled to a range of im (used hereafter to indicate the values of IM). This is analogous to increasing levels of force in pushover analysis. However, IDA provides a better indication of structural response as actual ground motion records are utilised. The edp (used hereafter to indicate the values of EDP) is noted at each im represented by a scaled record. Each time history analysis thus gives a pair of data $(e d p, i m)$ which defines a point in the IM-EDP domain. Joining such points obtained from the analyses using all scaled records results in the IDA curve for that ground motion record. This curve is usually characterised by a linear elastic region, followed by a transitional phase leading to a flat line indicating collapse [15]. IDA curves are generated here for all records in the suite using the three different IMs.

Step 2: Measure and compare the dispersion of responses

From the IDA curves, several edp data can be extracted for any value of $i m$. Using lognormal distribution to represent the variation of the edp data at a given im, the lognormal standard derivation of the edps at the required im is calculated. Repeating this for different im levels, the variation of lognormal standard deviation with respect to im is plotted. This is repeated for all three IMs to provide a comparison of their efficiency in reducing the record-torecord variation in structural response.

\section{INCREMENTAL DYNAMIC ANALYSIS (IDA)}

IDA is an inelastic time history based analysis procedure that offers a relatively accurate prediction of seismic demand and capacity [14]. An inelastic time history analysis program is required for IDA, which can be conducted by following the procedure summarised below:

1. Create a computational model of the structure in an inelastic dynamic analysis program.

2. Select a sufficient number of appropriate ground motion records. For this study, a suite of 20 ground motion records is used.

3. Choose an IM and scale the ground motion records to intensities ranging from a small im that produces an elastic response to an im large enough to cause collapse.

4. Choose an EDP that represents a critical/maximum response and has a reasonable correlation with damage. In this case, maximum absolute drift angle is used.

5. Conduct time history analysis with the scaled ground motions. This means conducting as many as 20 time history analyses for each ground motion record. Extract the edp from the output of each analysis.

6. Locate the $(e d p, i m)$ points from all analysis in the IM vs EDP plot and join these points to obtain an IDA curve for a ground motion record.

7. Scale all ground motion records and generate IDA curves for these records; i.e. repeat steps 5 and 6 for all ground motion records in the selected suite.

In this paper, inelastic dynamic analysis was conducted using the program RUAUMOKO 2D [16]. The batch file analysis mode was used extensively as a total of 5,600 runs (excluding those for sensitivity analysis) had to be conducted. Analyses were conducted in batches of 400 corresponding to 20 levels of appropriately scaled im for all 20 records. This was repeated for 14 single degree of freedom (SDOF) systems with periods ranging from $0.3 \mathrm{sec}$ to $2.0 \mathrm{sec}$. Records were scaled to give a range of im encompassing hazard levels corresponding to all limit states. The maximum im was intentionally set high to ensure that most records caused collapse of the structure. More efficient use of computing resources could be achieved through the use of algorithms that scale a record to capture the entire range of behaviour from elasticity to collapse. Only 12 scaling steps were found to be sufficient when using hunt and fill tracing algorithms [15]. Automatic extraction of results proved to be efficient and the potential for error was also reduced. Each batch of 400 runs required 20 minutes on a $1.6 \mathrm{GHz}$ processor computer. However, it should be noted that multi degree of 
Table 1: Ground motion records

\begin{tabular}{|l|l|l|l|l|l|l|l|}
\hline $\mathrm{ID}$ & Event & Year & Station & $\phi^{1}$ & $\mathrm{M}^{* 2}$ & $\mathrm{R}^{* 3}(\mathrm{~km})$ & PGA $(\mathrm{g})$ \\
\hline $\mathrm{Aa}$ & Loma Prieta & 1989 & Agnews State Hospital & 90 & 6.9 & 28.2 & 0.159 \\
\hline $\mathrm{Bb}$ & Imperial Valley & 1979 & Plaster City & 135 & 6.5 & 31.7 & 0.057 \\
\hline $\mathrm{Cc}$ & Loma Prieta & 1989 & Hollister Diff. Array & 255 & 6.9 & 25.8 & 0.279 \\
\hline $\mathrm{Dd}$ & Loma Prieta & 1989 & Anderson Dam & 270 & 6.9 & 21.4 & 0.244 \\
\hline $\mathrm{Ee}$ & Loma Prieta & 1989 & Coyote Lake Dam & 285 & 6.5 & 22.3 & 0.179 \\
\hline $\mathrm{Ff}$ & Imperial Valley & 1979 & Cucapah & 85 & 6.9 & 23.6 & 0.309 \\
\hline $\mathrm{Gg}$ & Loma Prieta & 1989 & Sunnyvale Colton Ave & 270 & 6.9 & 28.8 & 0.207 \\
\hline $\mathrm{Hh}$ & Imperial Valley & 1979 & El Centro Array \#13 & 140 & 6.5 & 21.9 & 0.117 \\
\hline $\mathrm{Jj}$ & Imperial Valley & 1979 & Westmoreland Fire Sta. & 90 & 6.5 & 15.1 & 0.074 \\
\hline $\mathrm{Kk}$ & Loma Prieta & 1989 & Hollister South \& Pine & 0 & 6.9 & 28.8 & 0.371 \\
\hline $\mathrm{Mm}$ & Loma Prieta & 1989 & Sunnyvale Colton Ave & 360 & 6.9 & 28.8 & 0.209 \\
\hline $\mathrm{Nn}$ & Superstition Hills & 1987 & Wildlife Liquefaction Array & 90 & 6.7 & 24.4 & 0.180 \\
\hline $\mathrm{Pp}$ & Imperial Valley & 1979 & Chihuahua & 282 & 6.5 & 28.7 & 0.254 \\
\hline $\mathrm{Qq}$ & Imperial Valley & 1979 & El Centro Array \#13 & 230 & 6.5 & 21.9 & 0.139 \\
\hline $\mathrm{Rr}$ & Imperial Valley & 1979 & Westmoreland Fire Sta. & 180 & 6.5 & 15.1 & 0.110 \\
\hline $\mathrm{Ss}$ & Loma Prieta & 1989 & WAHO & 0 & 6.9 & 16.9 & 0.370 \\
\hline $\mathrm{Tt}$ & Superstition Hills & 1987 & Wildlife Liquefaction Array & 360 & 6.7 & 24.4 & 0.200 \\
\hline $\mathrm{Uu}$ & Imperial Valley & 1979 & Plaster City & 45 & 6.5 & 31.7 & 0.042 \\
\hline $\mathrm{Vv}$ & Loma Prieta & 1989 & Hollister Diff. Array & 165 & 6.9 & 25.8 & 0.269 \\
\hline $\mathrm{Ww}$ & Loma Prieta & 1989 & WAHO & 90 & 6.9 & 16.9 & 0.638 \\
\hline
\end{tabular}

${ }^{1}$ Component, ${ }^{2}$ Moment Magnitudes, ${ }^{3}$ Closest Distances to Fault Rupture, and Source: PEER Strong Motion

Database, http://peer.berkeley.edu/smcat/

freedom (MDOF) models will take substantially longer processing times and hunt and fill algorithms may need to be used to reduce the processing time. Initially, PGA based scaling was used to conduct IDA and its result was postprocessed [17] to derive IDA curves with $\mathrm{S}_{\mathrm{a}}\left(\mathrm{T}_{1}, 5 \%\right)$ and NZS1170.5 based IM.

\subsection{Ground motion record Selection}

Twenty ground motion records, as shown in Table 1, were sourced from the Pacific Earthquake Engineering Research (PEER) Centre's strong motion database for this study to represent the typical range of possible earthquake scenarios. Following the current practice, the ground motions were chosen based on magnitude, distance from the nearby fault, and site conditions. These ground motions were recorded at $15-32 \mathrm{~km}$ from the closest point of the fault rupture and do not exhibit directivity effects. Magnitudes of these earthquakes vary from 6.5 to 6.9 and these records are from firm soil locations corresponding to USGS soil class C or D or NZS1170.5 [1] class C shallow soils.

By outlining the statistical variability of these 20 records, a more accurate measure of seismic demand imposed on the structure will be provided. The seismic response of structures subjected to a suite of records is herein assumed to have a lognormal distribution $[4,5]$. In order to estimate the median $e d p$ within a fraction $(X)$, the number of records $(n)$ required can be approximated using $n=4.0 \sigma^{2} / X^{2}$ where $\sigma$ is the lognormal standard deviation of the edps for a given value of im [18]. For the maximum interstory ductility of a MDOF structure dominated by the first mode response, a maximum value of 0.62 was recorded by Shome et al. [4] for the lognormal standard deviation $\sigma$. Consequently, the number of records required to estimate the median response to $\pm 25 \%$ is $4.0 \times 0.62^{2} / 0.25^{2} \approx 25$ records. However, use of additional records will result in lower levels of margin of error as the error is inversely proportional to the square root of the number of records used. Hence, reducing the error associated with 20 records by half will require 80 records. It should also

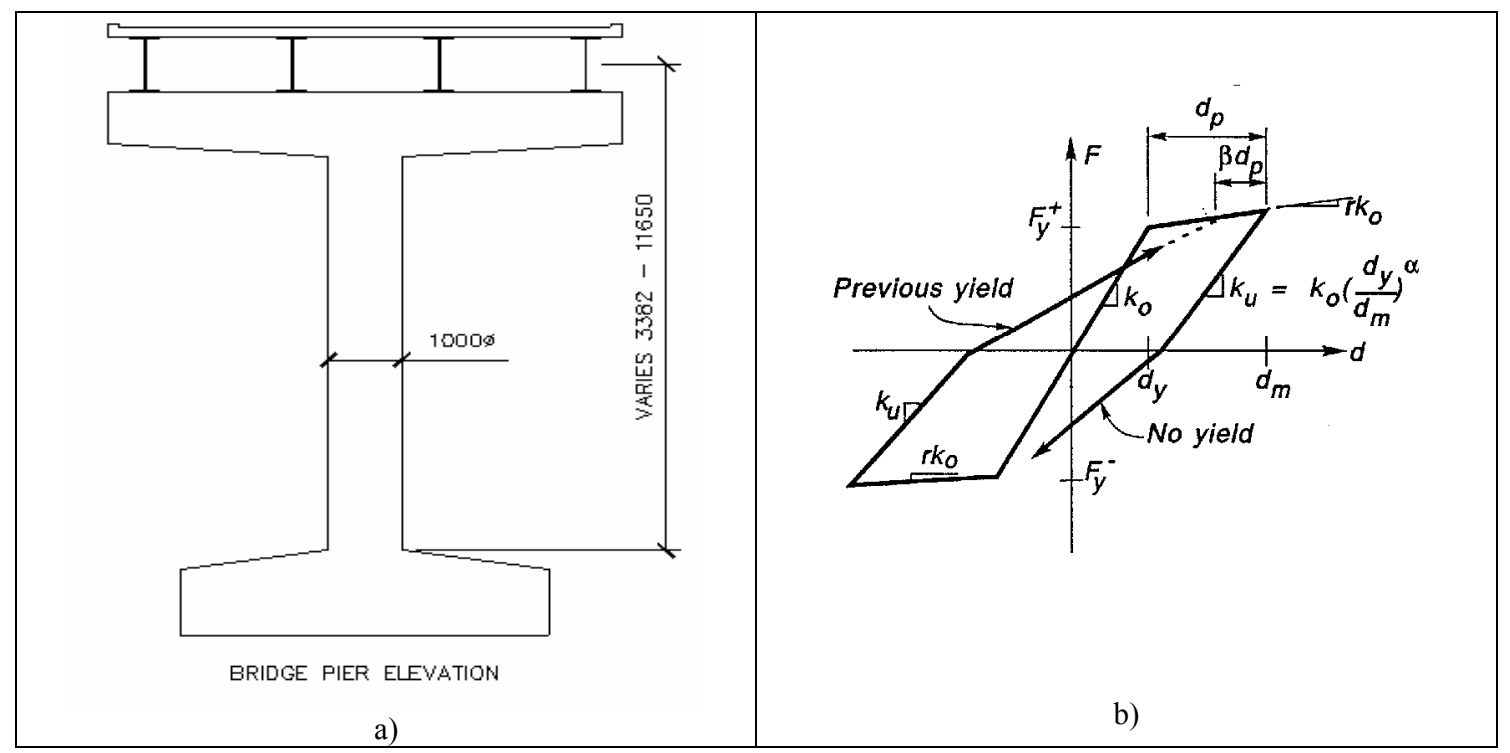

Figure 1: (a) Bridge pier elevation; and (b)Takeda hysteresis model 
be noted that the use of a more efficient IM producing lower levels of dispersion should allow for fewer records to be used in the analysis.

\subsection{Structural Model}

A one metre diameter reinforced concrete bridge pier as shown in Figure 1a was modelled as an SDOF system for conducting the IDA. This SDOF model was chosen for its simplicity and its ability to provide an adequate representation of structures dominated by the first mode response. Also by using an SDOF model, the effect of natural period on the structural response can be investigated by varying a single parameter - in this case height. The bridge pier used here is assumed to support a combined dead and live load of $2,000 \mathrm{kN}$, corresponding to $8 \%$ of its axial capacity (i.e. $0.08 \mathrm{f}_{\mathrm{c}}$ ' $\mathrm{A}_{\mathrm{g}}$ ). As shown in Figure $1 \mathrm{~b}$, a Takeda hysteresis loop with unloading factor of 0.3 and reloading factor of 0.5 was used to represent the nonlinear cyclic forcedeformation relationship of the SDOF system. Moreover, strength and stiffness degradation in the inelastic response phase is also accounted for in this hysteresis model. Viscous damping equal to $5 \%$ of the critical was assigned. For the same model, different natural first mode periods ranging from $0.3 \mathrm{sec}$ to $2.0 \mathrm{sec}$ were obtained by modifying the height while maintaining the diameter and loading. While doing so, the strength was not varied. Obviously, this affected the ductility capacity of the piers. Nevertheless, as the study compares the efficiency of different IMs which does not depend on the inelastic deformability of the piers with different periods, this difference is overlooked in the results and discussions.

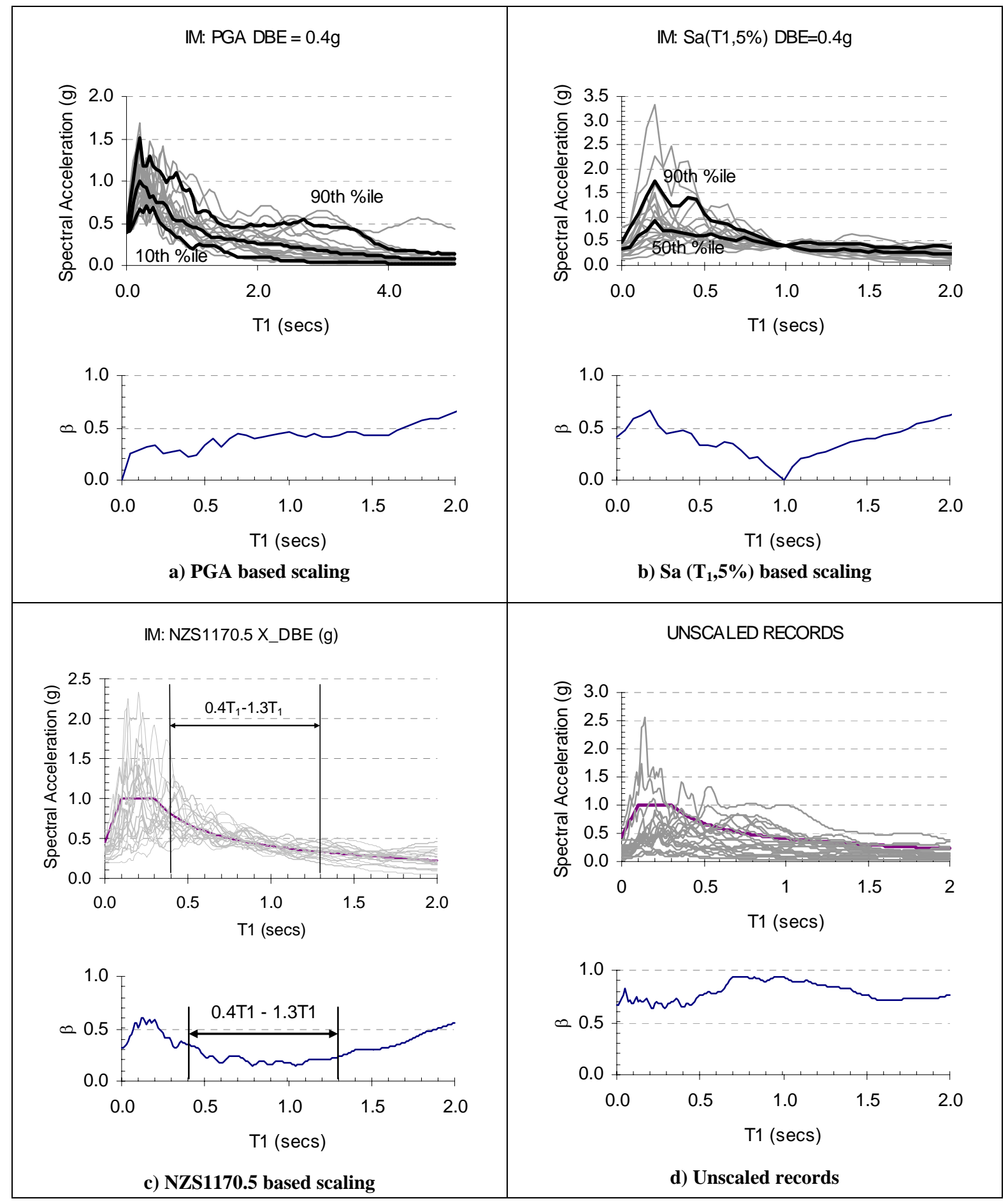

Figure 2: Elastic response spectra 


\section{EFFECTIVENESS OF INTENSITY MEASURES}

As mentioned earlier, appropriate choice of IM (likewise with EDP) affects the dispersion of the IDA curves. More effective IMs result in lower levels of variability of edp; and hence provide greater confidence in the demand obtained by using the same number of ground motion records. As shown in Figure 2, three IMs; namely PGA, $\mathrm{S}_{\mathrm{a}}\left(\mathrm{T}_{1}, 5 \%\right)$ and NZS1170.5 based IM which takes into account the spectral accelerations within a range of periods between $0.4 \mathrm{~T}_{1}$ and $1.3 \mathrm{~T}_{1}$ where $\mathrm{T}_{1}$ is the period of the first mode response of the structure, are used to derive IDA curves. This enables the comparison of the effectiveness of these three IMs over the range of periods analysed.

As the variation of edp given im has been shown to conform closely to a lognormal distribution $[4,5]$, the lognormal standard deviation (i.e. dispersion) of the edps for a given im measures the efficiency of the IM used. For the three IMs used in this study, dispersions are calculated and compared. For the first IM used in the study (i.e. PGA), the design basis earthquake (DBE) was considered to be $0.4 \mathrm{~g}$ which corresponds to the PGA of an earthquake that has a $10 \%$ chance of occurring in 50 years (i.e. return period of 475 years) for the design location (i.e. Wellington). The 20 original ground motion records were scaled to $0.4 \mathrm{~g}$ PGA (i.e. DBE) and the corresponding elastic response spectra are compared in Figure 2a, which shows the variation of lognormal standard deviations of $\mathrm{S}_{\mathrm{a}}$ at different first mode natural periods. Lognormal standard deviations (of $S_{a}$ ) and the response spectra for the unscaled records are also outlined in Figure $2 \mathrm{~d}$ for comparison with the other forms of scaling.

Similar scaling was conducted for $\mathrm{S}_{\mathrm{a}}\left(\mathrm{T}_{1}, 5 \%\right)$ after generating the elastic response spectra with $5 \%$ damping for each of the 20 original ground motion records. $\mathrm{S}_{\mathrm{a}}\left(\mathrm{T}_{1}, 5 \%\right)$ based scaling involves generating the elastic acceleration response spectrum of a record with $5 \%$ of critical damping and scaling the record to yield a constant value of $S_{a}$ at the first mode period $T_{1}$. Hence, response spectra of all records were scaled at the first mode period of the structure (used as 1 second for this figure) to the $\mathrm{S}_{\mathrm{a}}$ corresponding to the DBE. Following the commonly used period-dependent interrelationships between PGA and $S_{a}$ for different ranges of the design response spectrum, the $S_{a}$ values at DBE (and any other hazard intensity for that matter) can be calculated for a structure with a given period when the corresponding PGA values are known. As $\mathrm{S}_{a}\left(\mathrm{~T}_{1}, 5 \%\right)$ based scaling is conducted at a single period corresponding to the natural first mode period calculated based on elastic stiffness, it fails to capture higher order response modes and period elongation (due to softening of the structure) effects. As shown in Figure 2b, the elastic response spectra for the structural model with the first mode period of $1.0 \mathrm{sec}$ show a large variation in $\mathrm{S}_{\mathrm{a}}$ ordinates at smaller and larger periods. Consequently, the lognormal standard deviation plot for $\mathrm{S}_{\mathrm{a}}\left(\mathrm{T}_{1}, 5 \%\right)$ based scaling outlines a trough with zero dispersion at $\mathrm{T}_{1}$ and rapidly increasing dispersion levels away from $\mathrm{T}_{1}$.

Next, NZS1170.5 IM based scaling is conducted by performing least squares fitting to the logarithms of $\mathrm{S}_{\mathrm{a}}$ over the period range of $0.4 \mathrm{~T}_{1}-1.3 \mathrm{~T}_{1}$ for the 20 records. NZS1170.5 IM based scaling, which is done not only at the first mode period $T_{1}$ but over a range of periods, is intended to account for higher mode effects and decrease of stiffness (i.e. softening) in the inelastic phase of the structural response. In other words, including responses over a period range covering both sides of $T_{1}$ in the scaling method accounts for period elongation as the structural response is forced into the inelastic range (due to softening) as well as period shortening due to participation of higher frequency modes. As shown in Figure 2c, this results in a relatively low level of dispersion, which fluctuates around $\beta=0.2$ over the abovementioned period range.

A study addressing the issue of selection based on principal seismic characteristics and scaling have shown that there may not be a need for a careful site specific process for record selection by magnitude, distance and scaling [19]. However, it is still believed that factors such as the type of faulting, soil type and velocity pulses associated with near field effects would need to be considered prior to selecting ground motion records. In fact, it is often argued that scaling should be minimised as much as possible by using ground motion records with response spectra that match the elastic design spectrum as closely as possible. To this end, ground motion records are being categorised to enable ease of selection for given locations. Accordingly, NZS1170.5 [1] also recommends avoiding very large and very small scaling factors by eliminating records that need to be scaled by a factor $\mathrm{k}_{1}<0.33$ or $\mathrm{k}_{1}>3$. An addition, records that did not provide a good fit after scaling to the target spectra were also eliminated. This resulted in 5 records being rejected from the original suite of 20 records.

\section{RESULTS: EFFECT OF IM IN IDA CURVES}

Figure 3 shows IDA curves (IM vs EDP plots) for the structural model with $0.8 \mathrm{sec}$ natural period. The three IDA curves are for PGA, $\mathrm{S}_{\mathrm{a}}\left(\mathrm{T}_{1}, 5 \%\right)$ and NZS1170.5 IM, respectively. Note that the vertical axis is normalised with respect to the DBE; i.e. a normalised value of 1 represents the DBE. Note that the maximum considered earthquake (MCE) with a $2 \%$ chance of occurring in 50 years has approximately $0.8 \mathrm{~g}$ PGA for the assumed location. Hence, a value of 2 for the normalised intensity scale in the vertical axis represents the MCE (i.e. $0.8 \mathrm{~g} / 0.4 \mathrm{~g}=2$ ). Normalisation of the results is done to allow for a meaningful comparison of IDA results. While $\mathrm{S}_{\mathrm{a}}\left(\mathrm{T}_{1}, 5 \%\right)$ is almost equal to the PGA at $1 \mathrm{sec}$ period based on $\mathrm{S}_{\mathrm{a}}=\mathrm{PGA} / \mathrm{T}$ which is valid in the constant velocity range of elastic response spectra that normally encompasses $1 \mathrm{sec}$, the same is not true for other periods. For instance, as shown in Figure 4 , in the case of the $0.5 \mathrm{sec}$ period structural model the $\mathrm{S}_{\mathrm{a}}$ ordinate equals $0.68 \mathrm{~g}$, but it corresponds to a PGA (i.e. $\mathrm{S}_{\mathrm{a}}$ at $0 \mathrm{sec}$ ) of $0.4 \mathrm{~g}$. Thus comparing IDA results from a record scaled to $\mathrm{S}_{\mathrm{a}}(0.5,5 \%)=0.4 \mathrm{~g}$ and the same record scaled to $\mathrm{PGA}=0.4 \mathrm{~g}$ will produce erroneous conclusions. Values of $S_{a}$ are normalised with respect to the $\mathrm{S}_{\mathrm{a}}$ at the first mode period $\left(\mathrm{T}_{1}\right)$ and are represented as fractions and multiples of DBE; e.g. for the 0.5 second period structure $\mathrm{S}_{\mathrm{a}}(0.5,5 \%)=0.68 \mathrm{~g}$ is nominated as DBE whereas $0.4 \mathrm{~g}$ represents DBE for PGA based IM.

In addition to the IDA curves for the 20 ground motion records, Figure 3 also plots the $10^{\text {th }}, 50^{\text {th }}$ (median), and $90^{\text {th }}$ percentile IDA curves drawn based on the true variation of edps at each level of im. The difference in the $10^{\text {th }}$ and $90^{\text {th }}$ percentile IDA curves is representative of the variability in edp. PGA based scaling shows the greatest difference at DBE $(0.4 \mathrm{~g})$ between the $10^{\mathrm{th}}$ and $90^{\text {th }}$ percentile curves. The $10^{\text {th }}$ and $90^{\text {th }}$ percentile PGA based IDA curves give edps of $0.84 \%$ and $3.73 \%$, respectively at $i m=\mathrm{DBE}$; i.e. a ratio of 4.4 between the $90^{\text {th }}$ and $10^{\text {th }}$ percentile edps. On the other hand, $\mathrm{S}_{\mathrm{a}}\left(\mathrm{T}_{1}, 5 \%\right.$ )-based IDA curves give $0.89 \%$ and $2.66 \%$ edps corresponding to the $10^{\text {th }}$ and $90^{\text {th }}$ percentile response (i.e. a ratio of approximately 3 ). Similarly, the ratio of the $90^{\text {th }}$ to $10^{\text {th }}$ percentile edps at $i m=$ DBE for the NZS 1170.5 IM based IDA curves is 2.5. This simple comparison indicates that the hierarchy of the three IMs based on their capability to reduce record-to-record variation in structural response (i.e. efficiency) is: (i) NZS1170.5 based IM; (ii) $\mathrm{S}_{\mathrm{a}}\left(\mathrm{T}_{1}, 5 \%\right)$; (iii) PGA. 
It is normally acknowledged that the lognormal standard deviation of the edps at different im levels provides the best indication of the efficiency of the IM used. Figure 5 plots the lognormal standard deviations (dispersions) of the three IMs to compare their efficiencies. Note that there are four curves, one each for the three IMs and the fourth represents the case where three ground motion records are randomly selected (and scaled) according to the current NZ design practice. At DBE, the PGA based scaling shows a larger dispersion in comparison to $\mathrm{S}_{\mathrm{a}}\left(\mathrm{T}_{1}, 5 \%\right)$ and NZS1170.5 IM based scaling. This is in line with the differences in the $10^{\text {th }}$ and $90^{\text {th }}$ percentile $e d p s$ at $i m=$ DBE obtained from the IDA curves



Figure 3: IDA curves for 0.8 sec period structure with different IMs: a) PGA; b) $S_{a}\left(T_{1}, 5 \%\right)$; c) NZS1170.5 IM 


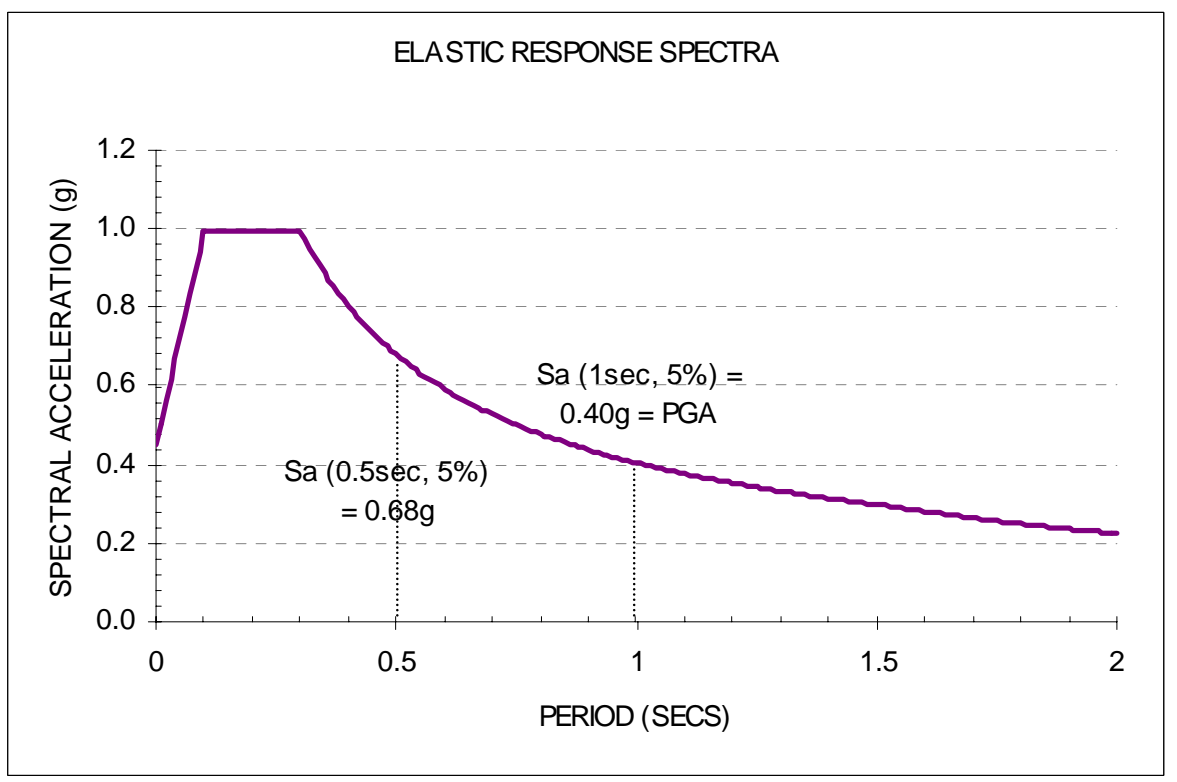

Figure 4: Normalisation of IM

generated by using the three different IMs. Interestingly, the dispersion profiles indicate little difference between the $\mathrm{S}_{\mathrm{a}}\left(\mathrm{T}_{1}, 5 \%\right)$ and NZS1170.5 IM based scaling for this structure.

To investigate further the relative merits of these two IMs, IDA was conducted for structural models with different natural periods. Figure 6 compares the lognormal standard deviations of the three different IMs for structural models with natural period of $0.5,1,1.5$, and $2 \mathrm{sec}$. As can be observed in all four plots, PGA is shown to consistently produce the highest level of dispersion in all structural models. Moreover, $\mathrm{S}_{\mathrm{a}}\left(\mathrm{T}_{1}, 5 \%\right)$ exhibits relatively small levels of lognormal standard deviation for im $<$ DBE range, and appears to be the best IM in terms of effectiveness up to approximately $i m=0.5 \mathrm{DBE}$. This is because as long as the response is elastic (which is the case with smaller im), the

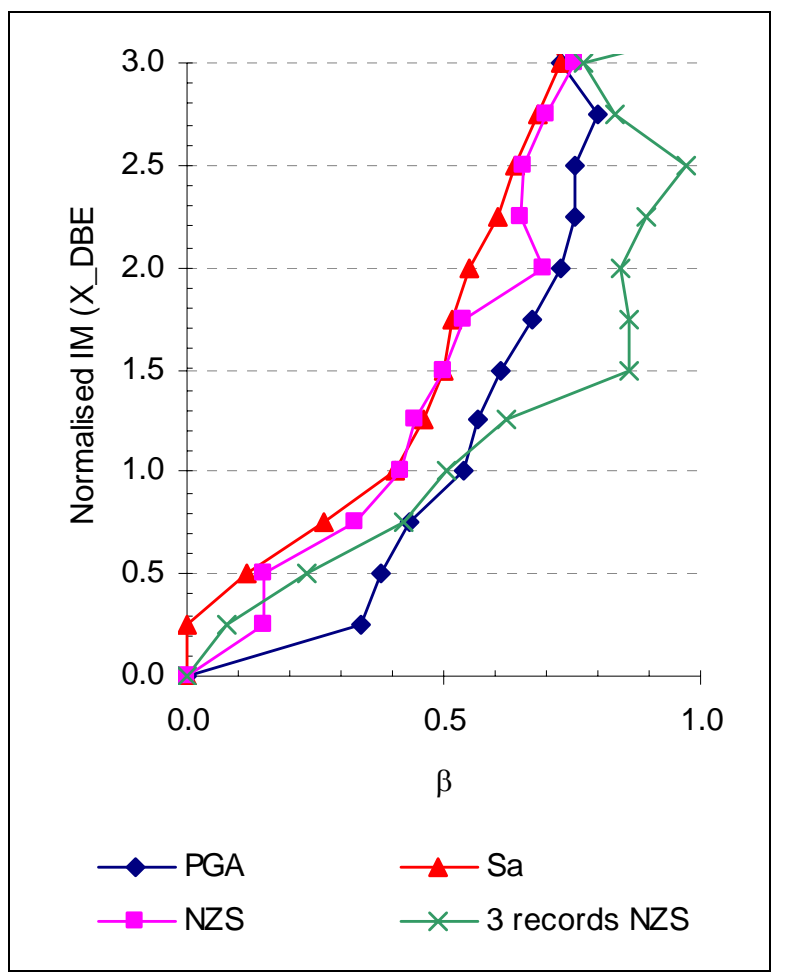

Figure 5: Dispersion for $T_{1}=0.8 \mathrm{sec}$ response of SDOF system (where higher frequency modes do not exist) is completely characterised by the elastic stiffness that controls the natural period, which is the basis of $\mathrm{S}_{\mathrm{a}}\left(\mathrm{T}_{1}\right.$, $5 \%$ ) based scaling.

Also understandably, $\mathrm{S}_{\mathrm{a}}\left(\mathrm{T}_{1}, 5 \%\right)$ proved to be as efficient as (if not more than) the NZS1170.5 IM for the $0.5 \mathrm{sec}$ period structure because the extent of inelastic response in the im range considered for this stiff structure is less likely to be significant. Expectedly, as the im increased the softening due to inelastic effects (which are taken into account in the analyses) became more prominent, and the dispersion associated with $\mathrm{S}_{\mathrm{a}}\left(\mathrm{T}_{1}, 5 \%\right)$ increased noticeably. On the other hand, NZS1170.5 IM based scaling is found to produce relatively low levels of dispersion in large im ranges as well. However, when using only 3 randomly selected ground motion records as stipulated in NZS1170.5 [1], the variation of the dispersion in various structural models is apparently inconsistent and unpredictable, indicating that this may not be an appropriate option. Designers could certainly have more confidence on the outcome if they use a suite of some 20 records instead. Note that once a reliable computational model is developed and verified, little additional time is needed to perform further analysis with additional records.

As outlined earlier, lower levels of dispersion provide higher confidence in the structural response. Take for instance the structural model with $1 \mathrm{sec}$ natural period shown in Figure $6 \mathrm{~b}$. The lognormal standard deviations $(\beta)$ at $i m=\mathrm{DBE}$ for PGA, $\mathrm{S}_{\mathrm{a}}\left(\mathrm{T}_{1}, 5 \%\right)$ and NZS1170.5 IM are $0.63,0.46$ and 0.42 , respectively. Based on these values, the confidence in the median response can be approximated using $n=4.0 \beta^{2} / X^{2}$. Therefore, the number of records required to estimate the median $e d p$ within a factor $\mathrm{X}$ (say 0.1 ; i.e. $\pm 10 \%$ ) is 159,85 and 71 for PGA, $S_{a}\left(T_{1}, 5 \%\right)$ and NZS1170.5 IM, respectively. The corresponding standard errors of estimation as percentage of the median can be calculated using $\beta \times 100 / \sqrt{ } \mathrm{n}$, which results in $14.1 \%, 10.3 \%$ and $9.4 \%$ for PGA, $\mathrm{S}_{\mathrm{a}}\left(\mathrm{T}_{1}, 5 \%\right)$ and NZS1170.5 IM, respectively. Therefore, it is important to use IMs that produce lower levels of dispersion in the response predicted using different ground motion records.

Following yet another approach of comparing the effectiveness of different IMs, Figure 7 compares the number of records required to estimate median edp response within a factor of $\pm 20 \%$. In addition to the four SDOF periods 


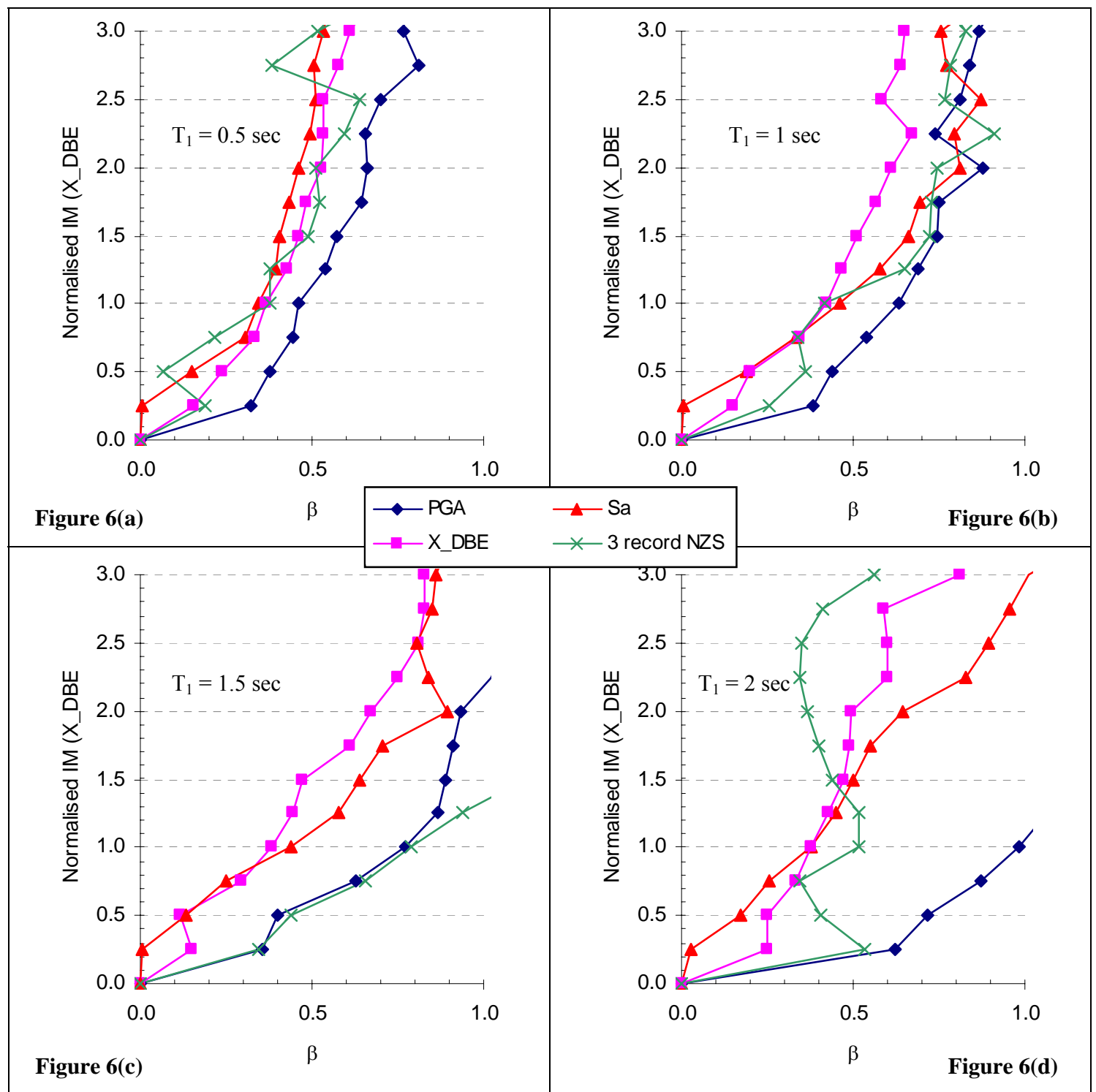

Figure 6: Comparisons of dispersions for structures with 0.5, 1.0, 1.5 and 2. 0 sec natural periods

discussed in Figure 6, Figure 7 includes one more case (with $\left.\mathrm{T}_{1}=0.3 \mathrm{sec}\right)$ which represents a very stiff structure. Interestingly, but perhaps not surprisingly, Figure 7 a shows that PGA based scaling required the fewest records to predict median response for the $T_{1}=0.3 \mathrm{sec}$ period structure, which indicates that PGA is the best IM for such short period structures. To be more specific, using PGA based scaling requires 18 and 34 records to predict the median response within a factor of $\pm 20 \%$ at $i m=\mathrm{DBE}$ and $\mathrm{im}=\mathrm{MCE}$, respectively, whereas the numbers are 33 and 42 for $S_{a}\left(T_{1}\right.$, $5 \%$ ) and 39 and 53 for NZS1170.5 IM, respectively. This is because this structure is so rigid that the response is close to the applied ground motion itself and as the scaling of PGA hence also means scaling of the peak response.

For larger structural periods though, PGA based scaling is found to require invariably the most number of records to generate the same level of confidence in the outcome. To be more blunt, the results suggest that PGA based scaling should not be used in case of longer period structures. Agreeing with Figure 6a, Figure $7 \mathrm{~b}$ also shows that $\mathrm{S}_{\mathrm{a}}\left(\mathrm{T}_{1}, 5 \%\right)$ is the most effective IM for the $0.5 \mathrm{sec}$ period structure. For structures with $1.0 \mathrm{sec}$ and longer period, the NZS1170.5 IM proves to be the most effective at reducing the dispersion of structural response, which is reflected by the consistently lowest number of ground motion records required to predict the median response. Furthermore, Figure 7 also highlights the need for a greater number of records to predict median response with the same level of confidence at MCE compared to that at DBE. This is because the structural response at MCE is invariably more inelastic than at DBE and none of the three IMs explicitly use inelastic spectra for scaling the records.

Although Figures 6 and 7 are plotted based on analyses of SDOF systems that deform in only one mode, these figures can be interpreted to qualitatively extrapolate the effect of higher frequency modes in the overall response of MDOF systems. Typically, the higher frequency modes are of concern in tall buildings, whose fundamental periods are in the range of a few seconds and whose higher order modes are closer to the predominant period of ground motions (say around $1 \mathrm{sec}$ ). Using information in Figures 6 and 7, one can clearly see that the overall response contributed mainly by the fundamental mode $\left(\mathrm{T}_{1}>>2 \mathrm{sec}\right)$ and significantly by the higher order modes $\left(\mathrm{T}_{\mathrm{n}} \sim 1 \mathrm{sec}\right)$ will be predicted more efficiently by NZS1170.5 IM than by $\mathrm{S}_{\mathrm{a}}\left(\mathrm{T}_{1}, 5 \%\right)$.

\section{NZS1170.5 PROVISIONS: NUMBER OF RECORDS AND EFFECTIVENESS OF THE $\mathrm{K}_{2}$ FACTOR}

As mentioned above, NZS1170.5 [1] recommends at least 


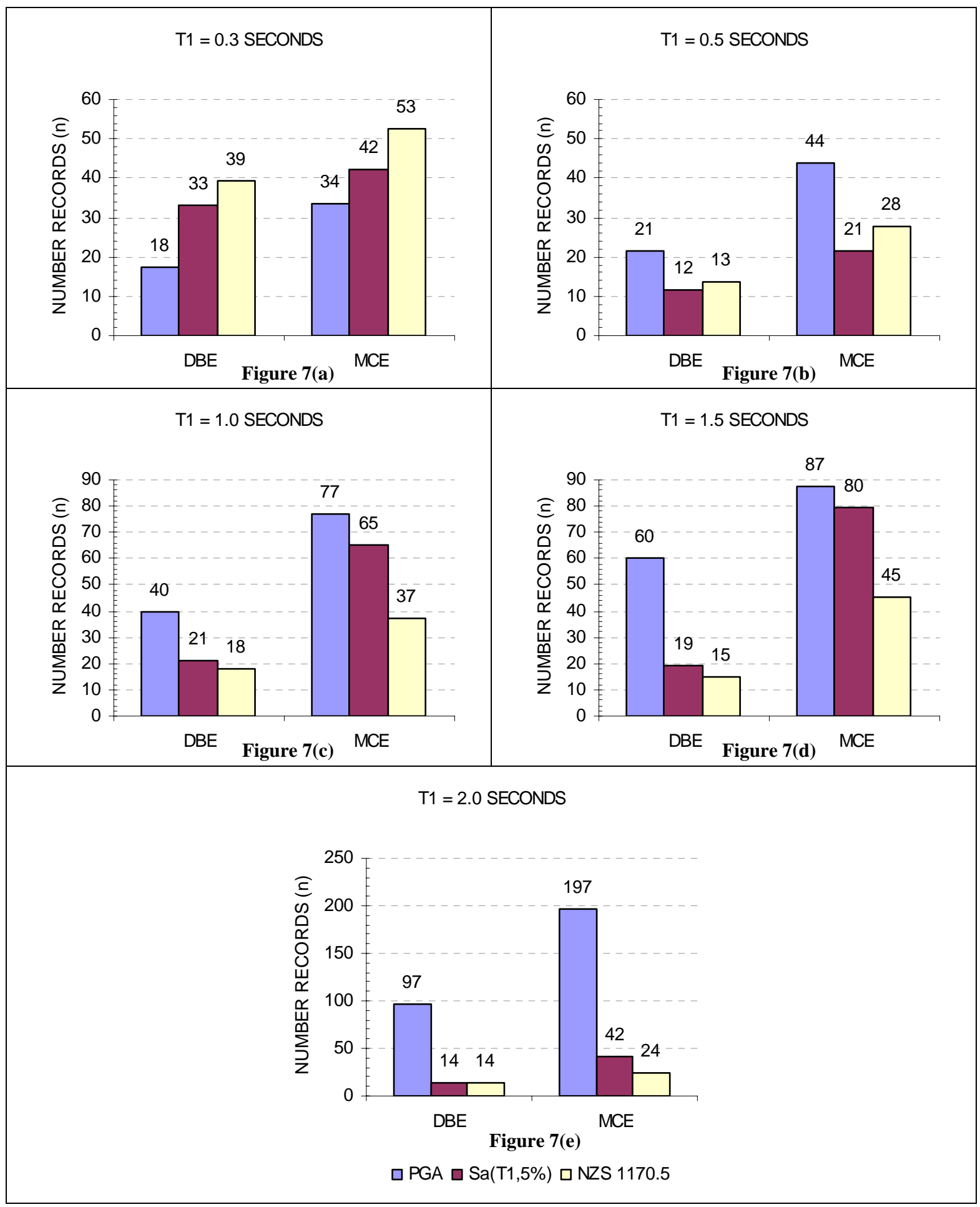

Figure 7: Number of records required to estimate the median response within a factor of $\pm 20 \%$

three records be used for estimating the seismic demand if nonlinear time history analysis be adopted for design purposes. It requires scaling the records using a scaling factor $\mathrm{k}_{1}$ which minimises in a least mean square sense the function $\log \left(\mathrm{k}_{1} \mathrm{~S}_{\mathrm{a}}{ }^{\text {record }} / \mathrm{S}_{\mathrm{a}}{ }^{\text {target }}\right)$ over the period range of interest between $0.4 \mathrm{~T}_{1}$ and $1.3 \mathrm{~T}_{1}$ where $\mathrm{T}_{1}$ is the natural first-mode period of the structure being designed. The three records could be randomly chosen; the only guideline specified in the standard for selection of ground motion records is that the scaling factor must lie between 0.33 and 3 . Hence, from the 20 ground motion records used in this study, any three among the 15 records that satisfy this criterion could be chosen. To explore the likely variation in the seismic demand due to random selection of three records, three different scenarios are investigated herein. These scenarios include using: (i) all 20 records;

(ii) all 15 records that satisfy the acceptance criteria $0.33<\mathrm{k}_{1}<3$; and

(iii) only three eligible records selected randomly from the suite.

The variations of dispersion of the edps at different values of NZS1170.5 im for these three different scenarios are compared in Figure 8. In this figure, 'NZS' denotes using all eligible records for which $0.33<\mathrm{k}_{1}<3$; 'NZS all records' denotes using all 20 records; and ' 3 records NZS' denotes using 3 eligible records randomly selected from the suite. The comparisons are shown for three structures with natural periods of $0.5,1.0$, and $1.5 \mathrm{sec}$. It can be seen in the plots that for smaller period structures the dispersion is low (because 


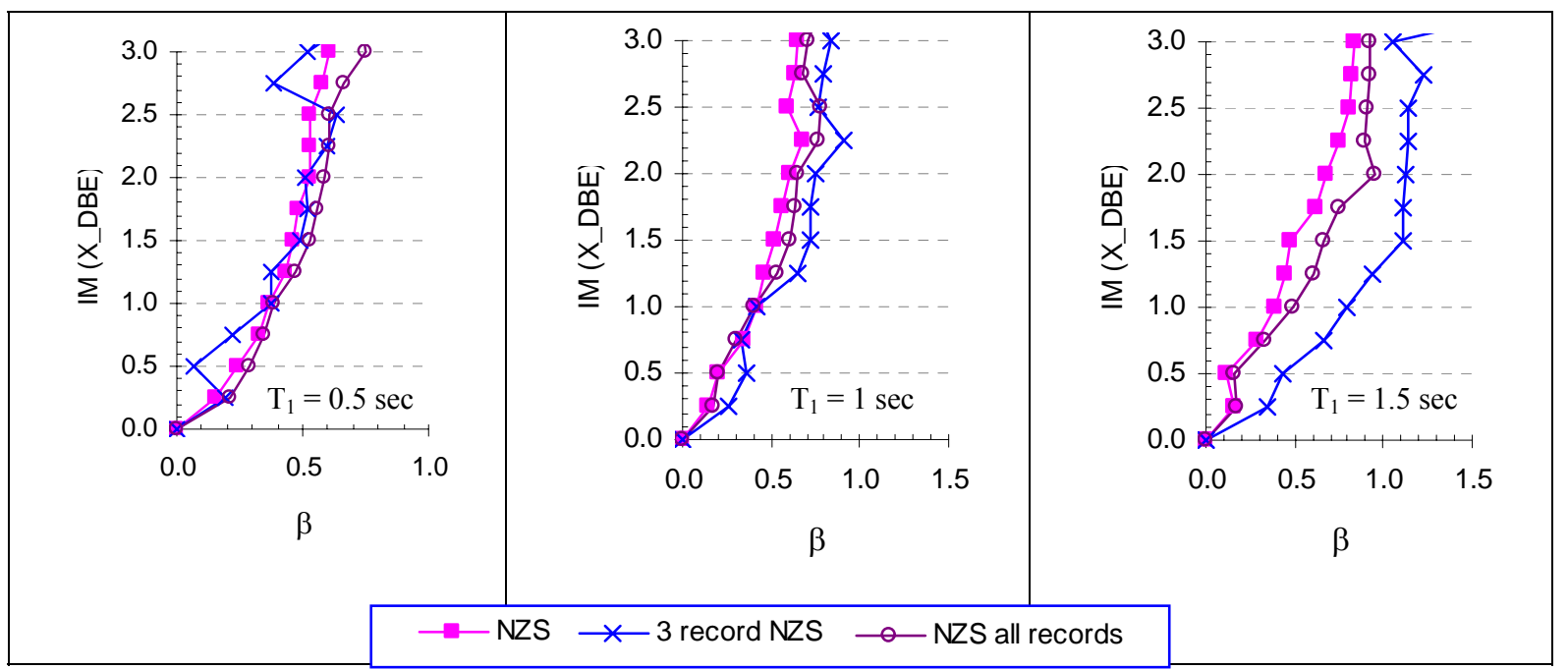

Figure 8: Comparisons of dispersions for $T_{1}=0.5 \mathrm{sec}, 1 \mathrm{sec}$ and $1.5 \mathrm{sec}$

the response of these relatively stiff structures is closer to the applied ground motion) and there is little difference between the three scenarios. When only 3 records are used, at some intensities the structural responses are clustered and indicate less variability in response resulting in artificially low dispersions. Hence, the only apparent observation from the 0.5 and $1.0 \mathrm{sec}$ structures, perhaps, is the zigzag nature of the dispersion profile of the " 3 records" scenario, thereby hinting at its lack of dependability.

The dispersions for the $1.5 \mathrm{sec}$ structure are consistently higher than those for the two stiffer structures. The plot also shows that using only 3 records gives dispersions which are roughly twice the dispersions obtained by using all 15 eligible records from the suite. As can be seen from Figures 5 and 6, using only 3 records for NZS1170.5 IM gives consistently higher dispersions than using $\mathrm{S}_{\mathrm{a}}\left(\mathrm{T}_{1}, 5 \%\right)$ and in many cases also higher than using PGA. It follows that the whole idea of using the complex IM suggested in NZS1170.5 [1] cannot be defended if only 3 records are to be used.

On the other hand, using all 20 records (including those for which the scaling factor is outside the range 0.33-3) slightly increases the dispersion compared to using only the eligible records. In fact, regardless of the structural period, using only the eligible records from the suite is always found to yield the least dispersion. Hence, the approach of screening the ground motion records as stipulated in NZS1170.5 [1] is undoubtedly beneficial. This also indicates that the efficiency of NZS1170.5 IM could be further increased (albeit slightly as indicated by the difference between using all 20 records and only the eligible records in Figure 8 ) by narrowing the allowable range of the scaling factor $\mathrm{k}_{1}$, say to $0.5-2$.

In addition to the component scaling factor $\mathrm{k}_{1}$, NZS1170.5 [1] also prescribes using a family factor $\mathrm{k}_{2}$ for each record (the value of which is not allowed to be less than 1) in the family of three earthquakes so that for every period in the range of interest, the response of at least one record is larger than the design/target spectrum. While doing so, all three records can be assigned $\mathrm{k}_{2}$ factors, but for simplicity only one record is rescaled here using the $k_{2}$ factor to ensure that its $S_{a}$ ordinates are at least equal to the design spectra ordinates within the range of $0.4 \mathrm{~T}_{1}-1.3 \mathrm{~T}_{1}$. This is equivalent to $\mathrm{k}_{2}=1.0$ (less than actual) for the other two records and more than needed for the rescaled record, thereby artificially inflating the dispersion compared to the actual NZS1170.5 approach. Nevertheless, as dispersion is not the topic of discussion here, this simple approach is adopted.

Figure 9 shows the IDA curves (using NZS1170.5 IM) of three randomly selected ground motion records that satisfy

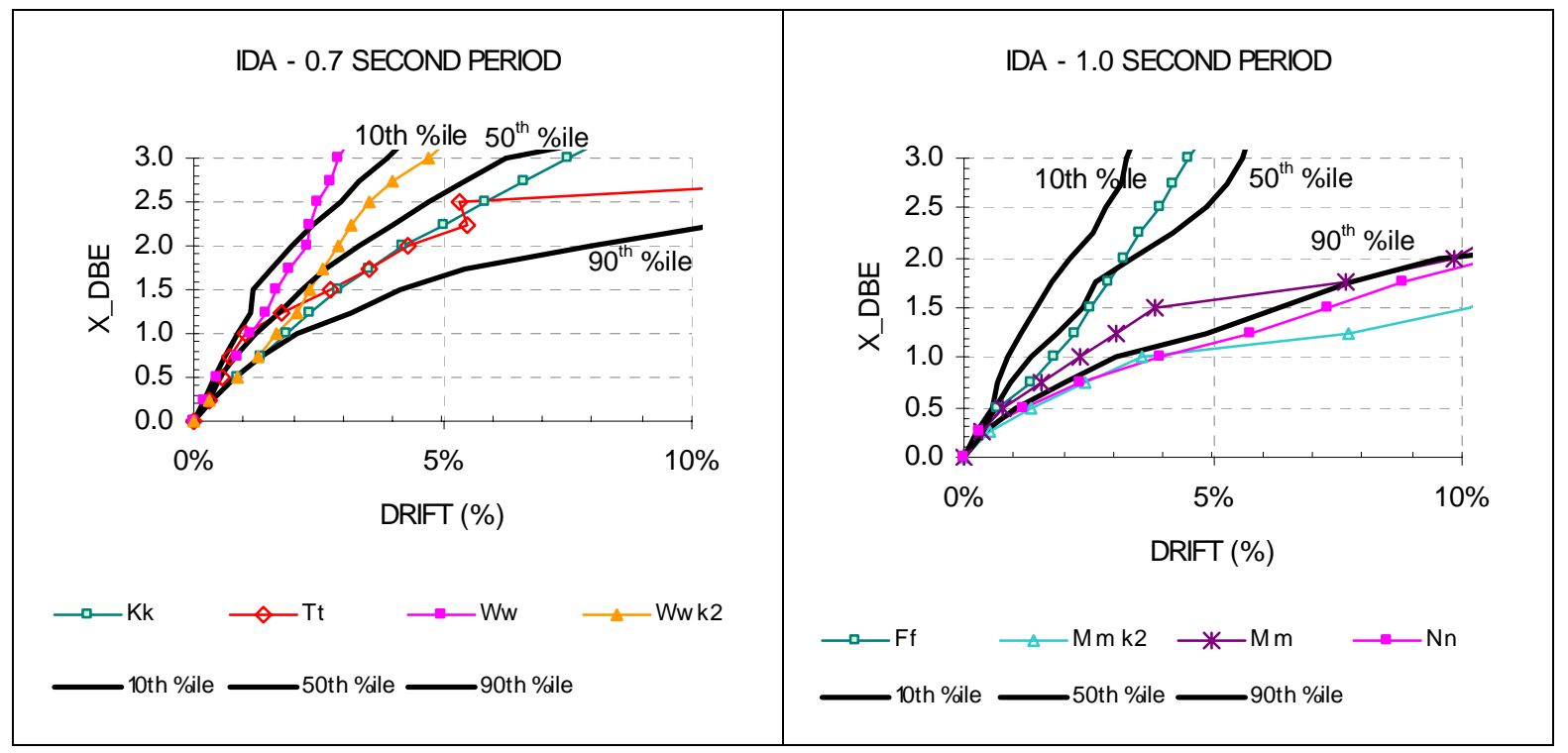

Figure 9: Effect of the family scale factor $k_{2}$ on the confidence of the predicted seismic demand 
the $0.33<\mathrm{k}_{1}<3$ criteria for structures with $0.7 \mathrm{sec}$ and 1.0 sec natural periods, respectively. The $10^{\text {th }}, 50^{\text {th }}$ and $90^{\text {th }}$ percentile IDA curves generated from the IDA data of all acceptable records from the suite are also superimposed on the figure to facilitate the discussion. In the $T_{1}=0.7 \mathrm{sec}$ case, the three ground motion records are $\mathrm{Kk}, \mathrm{Tt}$ and $\mathrm{Ww}$. As shown in the figure, record $\mathrm{Ww}$ produces the smallest response, even less than the $10^{\text {th }}$ percentile values at higher IMs. The other two ground motion records produce almost similar responses, consistently between the $50^{\text {th }}$ and $90^{\text {th }}$ percentile IDA curves. Applying the $\mathrm{k}_{2}$ factor to record $\mathrm{Ww}$ produces a response closer to the $50^{\text {th }}$ percentile response, still noticeably less than the response of the other two records without being inflated by the $\mathrm{k}_{2}$ factor, outlining that a single record modified by $\mathrm{k}_{2}$ factor to exceed the design spectra throughout the $0.4 \mathrm{~T}_{1}-1.3 \mathrm{~T}_{1}$ range does not necessarily result in it producing the largest response of the 3 records.

Among the three records ( $\mathrm{Ff}, \mathrm{Mm}$, and $\mathrm{Nn}$ ) randomly selected for the $\mathrm{T}_{1}=1 \mathrm{sec}$ structure, record $\mathrm{Mm}$ falls between the other two and also between the $50^{\text {th }}$ and $90^{\text {th }}$ percentile responses. Applying the $\mathrm{k}_{2}$ factor to $\mathrm{Mm}$ results in the response easily exceeding that of the $90^{\text {th }}$ percentile IDA curve. If the $\mathrm{k}_{2}$ factors were applied to all three records as suggested in NZS1170.5 [1], record Nn which is already (without $\mathrm{k}_{2}$ factor) beyond the $90^{\text {th }}$ percentile line, would definitely give a very high response. As the recommendation is to adopt the maximum among the three predictions, the design demand in this case would have been extremely conservative. These two cases clearly indicate that applying factor $k_{2}$ to all three records will produce a maximum response which is highly likely to exceed the $90^{\text {th }}$ percentile response, and that too by a big margin in many cases. Note that in a typical probability distribution function such as Gaussian or lognormal which have been used commonly to represent the variation in edps [5], a small increase in the cumulative probability beyond $90 \%$ corresponds to a big increase in the value of the edp. As this level of confidence can hardly be justified for any performance requirement (perhaps, except for the life safety criteria), the use of $k_{2}$ factor to scale all three records as currently specified in NZS1170.5 [1] significantly overestimates the seismic demand thereby leading to an overly conservative design if the nonlinear time history analysis method is used in seismic design.

\section{CONCLUSIONS}

Based on the computational investigation described in this paper, the following conclusions can be drawn:

1. Significant record-to-record variation in structural response will invariably occur even though the ground motion records have been scaled to the same level of intensity. Incremental dynamic analysis (IDA) can be conducted to assess the degree of this record-to-record variation that can be quantified using dispersion factors (i.e. standard deviation calculated assuming lognormal distribution).

2. By using more 'efficient' intensity measures (IM), the dispersions can be significantly reduced. It is found that the NZS1170.5 IM (based on least squares fit of logarithms of spectral accelerations at periods within a range of 0.4-1.3 times the natural period of the structure) is found to be slightly more efficient than the $5 \%$ damped spectral acceleration at the natural period; i.e. $\mathrm{S}_{a}\left(\mathrm{~T}_{1}, 5 \%\right)$, and somewhat more efficient than the peak ground acceleration (PGA). The reason for the NZS1170.5 based IM being the most efficient is its ability to incorporate the effects of softening $\left(T>T_{1}\right)$ due to inelastic response and the contribution of higher order modes $\left(T<T_{1}\right)$ in the scaling process.

3. Although $\mathrm{S}_{\mathrm{a}}\left(\mathrm{T}_{1}, 5 \%\right)$ is found to provide a similar level of dispersion as NZS1170.5 IM up to 0.5DBE and at all intensity levels for lower period structures. Given the small difference between the dispersions using $\mathrm{S}_{\mathrm{a}}\left(\mathrm{T}_{1}\right.$, $5 \%$ ) and NZS1170.5 IM in other cases, too, and given that processing the records using the NZS1170.5 IM is significantly more cumbersome, it is a close call to select the IM for SDOF systems. Nevertheless, the SDOF system analytical results were scrutinised to infer that the difference in efficiency is likely to be more in larger period MDOF systems where higher order modes are likely to play a significant role in the overall response.

4. The aforementioned gain in efficiency is true only if a significant number of records (20 in this study) are used. If only three records (allowed in NZS1170.5) are used, the efficiency of NZS1170.5 IM is consistently less than $\mathrm{S}_{\mathrm{a}}\left(\mathrm{T}_{1}, 5 \%\right)$, thereby making the use of the complex NZS1170.5 IM difficult to defend. On the other hand, the guideline to select records based on the $0.33<\mathrm{k}_{1}<3$ criteria has been found helpful in further enhancing the efficiency of the NZS1170.5 IM, and further narrowing the allowable range of $\mathrm{k}_{1}$ will be beneficial.

5. The use of the family scale factor $k_{2}$ to scale all three records is found to result in significant overestimation of the demand leading to an unintended overly conservative design if time history analysis is used for seismic design purpose.

\section{REFERENCES}

1. NZS1170.5. (2004). New Zealand Standard, Structural Design Actions Part 5: Earthquake Actions - New Zealand. Standards New Zealand, Wellington.

2. Krawinkler, H. and Miranda, E. (2004). Performancebased earthquake engineering. In Earthquake Engineering: From Engineering Seismology to Performance-Based Engineering, Edited by Bozorgnia, Y. and Bertero, V.V. CRC Press, Boca Raton, FL.

3. Dhakal, R.P. and Mander, J.B. (2006). Financial risk assessment methodology for natural hazards. Bulletin of the New Zealand Society of Earthquake Engineering 39(2):91-105.

4. Shome, N., Cornell, C.A., Bazzurro, P. and Carballo, J.E. (1998). Earthquakes, records, and nonlinear responses. Earthquake Spectra 14(3):469-500.

5. Mander, J.B, Dhakal, R.P, Mashiko, N. and Solberg, K.M. (2007). Incremental dynamic analysis applied to seismic financial risk assessment of bridges. Engineering doi:10.1016/j.engstruct.2006.12.015 (In Press).

6. Abrahamson, N.A. and Silva, W.J. (1997). Empirical response spectral attenuation relations for shallow crustal earthquakes. Seismological Research Letters 68:94-127.

7. Shome, N. and Cornell, C.A. (1999). Probabilistic Seismic Demand Analysis of Nonlinear Structures. Report No. RMS-35, RMS Program, Stanford University, Stanford, CA.

8. Cornell, C.A. and Luco, N. (1999). The effects of connection fractures on steel moment resisting frame seismic demand and safety: A report on SAC Phase II task 5.4.6. Report No. SAC/BD-99/03, SAC Joint Venture, Sacramento, California.

9. Luco, N. and Cornell, C.A. (2007). Structure-specific 
scalar intensity measure for near-source and ordinary earthquake ground motions. Earthquake Spectra 23(2):357-392.

10. Tothong, P. and Luco, N. (2007). Probabilistic seismic demand analysis using advanced ground motion intensity measures. Earthquake Engineering and Structural Dynamics (In Press).

11. Baker, J.W. and Cornell, C.A. (2005). A vector-valued ground motion intensity measure consisting of spectral acceleration and epsilon. Earthquake Engineering and Structural Dynamics 34(10):1193-1217.

12. Luco, N. (20020. Probabilistic seismic demand analysis, SMRF connection fractures, and near source effects. $\mathrm{PhD}$ Thesis, Dept. of Civil and Environmental Engineering, Stanford University, California.

13. Singh, S. (2006). Earthquake Record Selection for Time History Analysis. ME Project Report, Dept. of Civil Engineering, University of Canterbury.

14. Vamvatsikos, D. and Cornell, C.A. (20020. Incremental dynamic analysis. Earthquake Engineering and Structural Dynamics 31(3):491-514.
15. Vamvatsikos, D. and Cornell, C.A. (2004). Applied incremental dynamic analysis. Earthquake Spectra 20(2):523-553.

16. Carr, A.J. (2004). RUAUMOKO 2D: Inelastic Dynamic Computer Program. Computer Program Library, Department of Civil Engineering, University of Canterbury, Christchurch, New Zealand.

17. Vamvatsikos, D. and Cornell, C.A. (2005). Developing efficient scalar and vector intensity measures for IDA capacity estimation by incorporating elastic spectral shape information. Earthquake Engineering and Structural Dynamics 34(13):1573-1600.

18. Benjamin, J.R. and Cornell, C.A. (1970). Probability, Statistics, and Decision for Civil Engineers. McGrawHill, New York.

19. Iervolino, I. and Cornell, C.A. (2005). Record selection for nonlinear seismic analysis of structures. Earthquake Spectra 21(3):685-713.

20. Dhakal, R.P., Mander, J.B. and Mashiko, N. (2006). Identification of critical ground motions for seismic performance assessment of structures. Earthquake Engineering and Structural Dynamics 35(8):989-1008. 